\title{
Abnormal growth factor and cytokine expression in Dupuytren's contracture
}

\author{
K S Baird, J F Crossan, S H Ralston
}

\begin{abstract}
Aim-To analyse patterns of gene expression for peptide regulatory factors in patients with Dupuytren's contracture.

Methods-Tissue samples (palmer fascia) from 12 patients with Dupuytren's contracture and 12 controls were studied using the reverse transcription/polymerase chain reaction (RT/PCR) technique.

Results-Tissue from patients with Dupuytren's contracture expressed a higher percentage of peptide regulatory factors than that of controls: interleukin$1 \alpha(83 \% v 16 \% ; \mathrm{p}<0.01)$; interleukin-1 $\beta$ $(66 \% v 8 \%$; $<<0.01)$; transforming growth factor $\beta(75 \%$ v $25 \%$; $<0.02)$; and basic fibroblast growth factor $(66 \% v$ 25\%; $p<0.05$ ). Platelet derived growth factors $\alpha$ and $\beta$ were also expressed more commonly $(66 \% v 33 \%$ and $25 \% v 16 \%$, respectively), but these differences were not significant.

Conclusions-The increased prevalence of expression for the above mRNAs in Dupuytren's tissue is relevant as interleukin-1, basic fibroblast growth factor, and transforming growth factor $\beta$ stimulate the growth of fibroblasts and transforming growth factor $\beta$ also enhances production of collagen and other extracellular matrix proteins. Excessive local release of these peptide regulatory factors may have an important role in the pathogenesis of Dupuytren's contracture.
\end{abstract}

(F Clin Pathol 1993;46:425-428)

Dupuytren's contracture is a disease of unknown cause characterised by an abnormal fibroblast proliferation and matrix deposition affecting the palmar and plantar fasciae. ${ }^{1}$ The condition has been extensively studied at a histological and ultrastructural level and various abnormalities of fibroblast morphology and tissue composition have been described. These include histological evidence of abnormal fibroblast proliferation and matrix production; the appearance of "myofibroblasts" which contain increased amounts of actin ${ }^{1}$; an increase in the ratio of type III to type I collagen in extracellular matrix ${ }^{2}$; an increase in matrix proteoglycan content ${ }^{3}$; and raised free radical content of affected tissue. ${ }^{4}$

In some cases, the disease seems to be inherited as an autosomal dominant trait ${ }^{5}$; in others, it may be precipitated by an injury to the hand. Its prevalence has also been reported to be raised in several medical conditions including cirrhosis, diabetes mellitus, congential epilepsy ${ }^{6}$ and HIV infection, ${ }^{7}$ although the basic cause of the fibrotic process remains unclear in all of the above conditions.

The histological features of Dupuytren's contracture, coupled with the observation that cultured cells from affected nodules exhibit characteristics of a transformed phenotype, ${ }^{8}$ suggested to us that the condition may be due to an abnormality in growth factor regulation-a hypothesis that is supported by the observation that myofibroblast proliferation in breast cancer may be induced by growth factors released by the tumour cells. ${ }^{9}$ In this study, therefore, we sought to test this hypothesis by using the technique of reversetranscription/polymerase chain reaction (RT/ PCR $)^{10}$ to analyse expression of cytokines and growth factors (peptide regulatory factors) known to have effects on fibroblast growth and activity, in RNA extracted from palmar fascia in patients with Dupuytren's contracture.

\section{Methods}

Tissue samples were obtained from 12 patients undergoing surgical fasciectomy for Dupuytren's contracture. Tissue was preferentially sampled from "nodular" areas of excised specimens, because we considered that these may have been most active in terms of peptide regulatory factor expression. ${ }^{4}$ Control tissues were obtained for comparison, comprising samples of palmar fascia in 12 patients undergoing hand surgery for other reasons (mostly carpal tunnel decompression). In all cases the tissues were snap frozen in liquid nitrogen immediately after surgical removal. After partial rewarming, the sample was homogenised and total RNA extracted by the acid phenol-guanidinium thiocyanatechloroform method. ${ }^{11}$ The RNA was quantitated by spectrophotometry, and a standard amount $(5 \mu \mathrm{g})$ reverse-transcribed using a genetically engineered MuMLV reverse transcriptase (Superscript, Gibco/BRL). The resulting complementary DNA (cDNA) was dissolved in $100 \mu$ l sterile distilled water and 1 in 20 of the cDNA $(5 \mu \mathrm{l})$ was used as the template for each polymerase chain reaction (PCR). The PCR was carried out under standard reaction conditions in a $50 \mu \mathrm{l}$ volume. Appropriate safeguards were used to avoid 
false positive results due to external contamination. ${ }^{12}$ Purified Taq polymerase and reaction buffer $(1.5 \mathrm{mM} \mathrm{Mg} \mathrm{Cl})$ were supplied by Boehringer-Mannheim (UK) and oligonucleotide primers (see below) were used at a final concentration of $0.5 \mu \mathrm{M}$ each. Thirty five cycles of amplification were used as standard, one cycle comprising a "melting" step of $94^{\circ} \mathrm{C}$ for 40 seconds, an "annealing" step of $55^{\circ} \mathrm{C}$ for 60 seconds, and an "extension" step of $72^{\circ} \mathrm{C}$ for 90 seconds. During the first cycle, the melting step was extended to 120 seconds and during the last cycle, the extension step was extended to 5 minutes.

Oligonucleotide primers (24-30 mers, in some cases incorporating additional bases to introduce restriction sites at the $5^{\prime}$ end) were designed on the basis of published sequences with the aid of the GCG sequence analysis software package ${ }^{13}$ and prepared using an automated oligonucleotide synthesiser. Primer recognition sites on the respective mRNAs and predicted PCR product sizes were as fol-

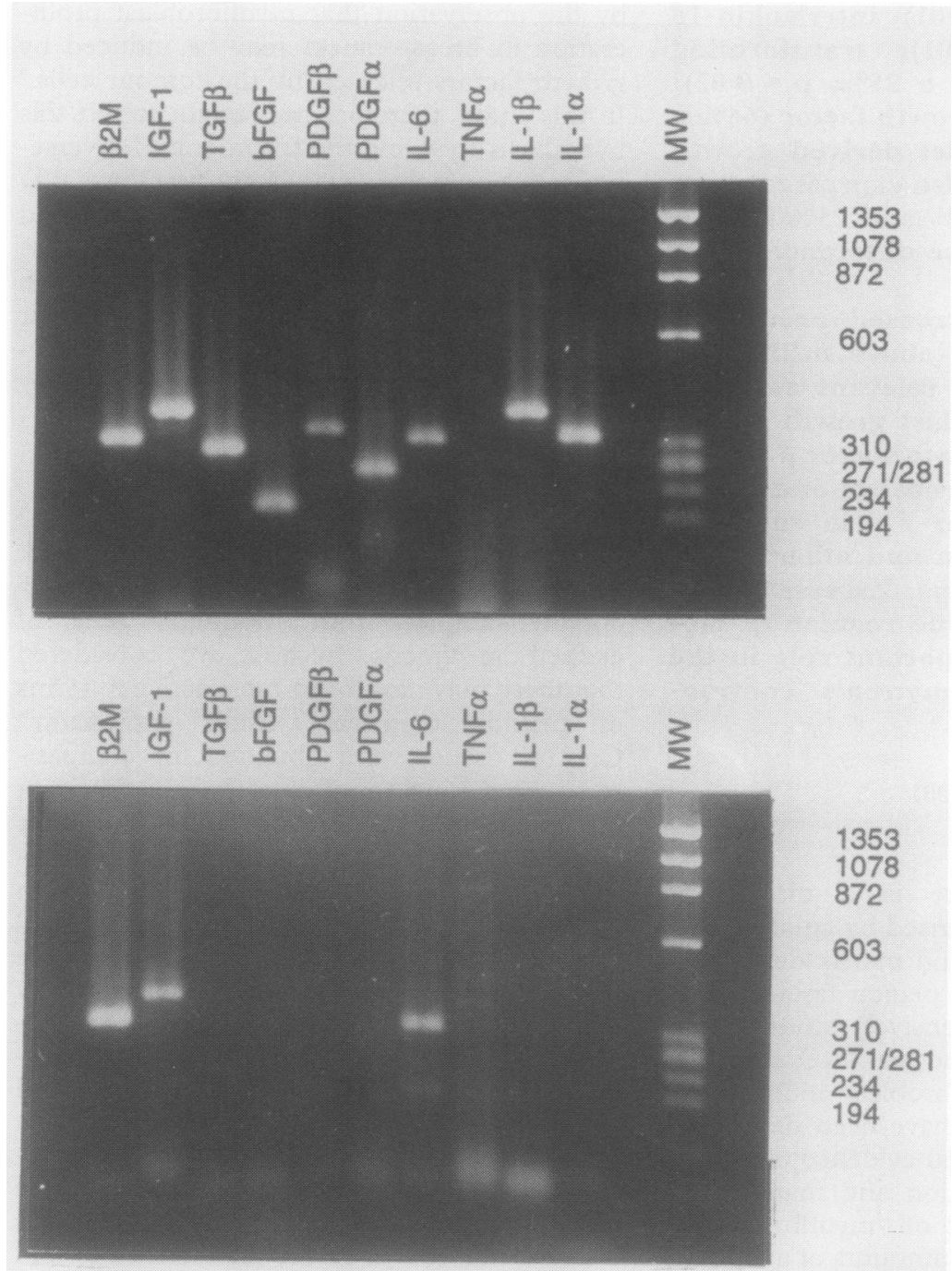

Figure 1 Agarose gel electrophoresis of PCR products from cDNA derived from palmar tissue in patients with: Top panel: Dupuytren's contracture. Several bands are visible, showing evidence of expression for $I L-1 a, I L-1 \beta, I L-6, P D G F a, P D G F \beta, T G F \beta, \beta F G F$ and $\beta 2 M$. Bottom panel: Control palmar fascia (carpal tunnel syndrome), showing expression of IL-6, $\beta 2 M$ and IGF-1 only. $M W=$ molecular weight marker (phiX174/HaelII digest). lows: IL-1 $a$ bases 300-611 (product size 324 base pairs); IL-1 $\beta$ : 94-459 (376 base pairs); TNFa: $15-452$ (450 base pairs); IL-6:188484 (313 base pairs); TGF $\beta$ : 1252-1551 (299 base pairs); IGF-1:224-605 (381 base pairs); PDGFa: 490-747 (257 base pairs); PDGF $\beta$ : 1310-1642 (332 base pairs); bFGF: 575778 (203 base pairs); $\beta 2 M: 24-346$ (322 base pairs). In all cases the primer recognition sites were designed to reside in separate exons or at intron-exon boundaries of the genomic sequence, ensuring specificity for amplification of mRNA (cDNA), rather than genomic DNA. The identity of the PCR products was confirmed by their predicted size on agarose gel electrophoresis and by restriction analysis, in which "diagnostic" fragments of a specific size are obtained when the PCR product is digested by a restriction enzyme with a recognition site within the product in question (data not shown, full information on restriction enzymes used, and fragments generated available on request). Reaction products $(12 \mu \mathrm{l})$ were analysed by electrophoresis through $2 \%$ agarose gels stained with ethidium bromide, visualised by transillumination under ultraviolet light at $302 \mathrm{nM}$.

The $\chi^{2}$ test and Wilcoxon's test were used for statistical analysis.

\section{Results}

Twelve patients with Dupuytren's contracture (11 men and one woman) and twelve controls (nine men and three women) were studied. The median (range) age of the patients was 47 (29-63) years in the Dupuytren's contracture and 52 (30-67) years in the control group.

Typical results of the RT/PCR analysis for a patient with Dupuytren's contracture and a control are shown in fig 1 . In the top panel (Dupuytren's contracture tissue) multiple bands of the appropriate molecular weight are visualised indicating expression of IL-1 $a, \mathrm{IL}$ $1 \beta$, IL-6, bFGF, TGF $\beta$, PDGF $a$ and PDGF $\beta$, IGF-1 and $\beta 2 \mathrm{M}$. In the bottom panel (control tissue) only IL-6, IGF-1, and $\beta 2 \mathrm{M}$ are expressed. There was some individual variation in the expression of other peptide regulatory factors in patients with Dupuytren's contracture and controls (individual data not shown), but the total number of peptide regulatory factors expressed (excluding $\beta 2 \mathrm{M}$ ) was significantly greater in Dupuytren's contracture than in controls. Thus the median (range) number of factors expressed was $6 \cdot 0(4-8)$ in Dupuytren's contracture tissue, compared with $3 \cdot 5(2-5)$ in control tissue $(p<0.002) . \beta 2 M$ was itself expressed in all cases; in further experiments where the cDNA was serially diluted between 10-10 000-fold and subjected to 35 cycles of $P C R$, a positive $\beta 2 M$ signal remained visible down to 1 in 1000 dilution in nine patients and eight control cDNAs, and down to 1 in 10000 dilution in the remaining three patients and four control cDNAs.

These experiments confirm that the relative amounts of cDNA and the efficiency of 
the reverse transcription reactions did not differ significantly in the two groups. When the patterns of expression were analysed in terms of the individual peptide regulatory factors studied (fig 2), expression of IL-1 $a, \mathrm{IL}-1 \beta$, TGF $\beta$ and $\mathrm{bFGF}$ was significantly more common in Dupuytren's contracture tissue than in control tissue: IL-1a 10/12 (83\%) Dupuytren's contracture $v 2 / 12(16 \%)$ (control), $\chi^{2}=10.6, \mathrm{p}<0.01$; IL-1 $\beta 8 / 12(66 \%) v$ $1 / 14(8 \%), \chi^{2}=8 \cdot 7, \mathrm{p}<0.01 ;$ TGF $\beta$ 9/12 $(75 \%)$ v $3 / 12(25 \%), \chi^{2}=6.0, \mathrm{p}<0.01$; bFGF 8/12 (66\%) $v 3 / 12(25 \%), \chi^{2}=4 \cdot 1$, p $<0.05$. PDGFa and PDGF $\beta$ were also expressed more frequently in Dupuytren's contracture, but the difference between the groups was not significant: PDGF $\alpha$ 8/12 $(66 \%)$ v $4 / 12(33 \%) \quad \chi^{2}=2 \cdot 6$, NS and $\operatorname{PDGF} \beta 3 / 12(25 \%) v 2 / 12(16 \%)=\chi^{2} 0 \cdot 2$, NS. Some peptide regulatory factors, including IL-6 (100\% v 91\%), TNFa (41\% v 50\%) and IGF-1 $(100 \% v 91 \%)$ were expressed in a similar proportion of patient and control tissues. Although the number of patients studied was relatively small, there was no obvious relation between the type and number of peptide regulatory factors expressed according to the patients' age or sex, either in the Dupuytren's contracture group or the controls (data not shown).

\section{Discussion}

Although the RT/PCR technique, as used here, cannot be used to measure the absolute quantity of different mRNAs in the original tissue extracts, ${ }^{10}$ differences in the relative abundance of specific mRNAs between different patient groups can be assessed based on the presence or absence of a PCR product after a standard number of cycles have been completed. ${ }^{14}$ Using this technique, we found that the pattern of peptide regulatory factor expression in Dupuytren's contracture was quite distinct from that in control tissue. Although both tissues expressed IL-6, IGF-1,

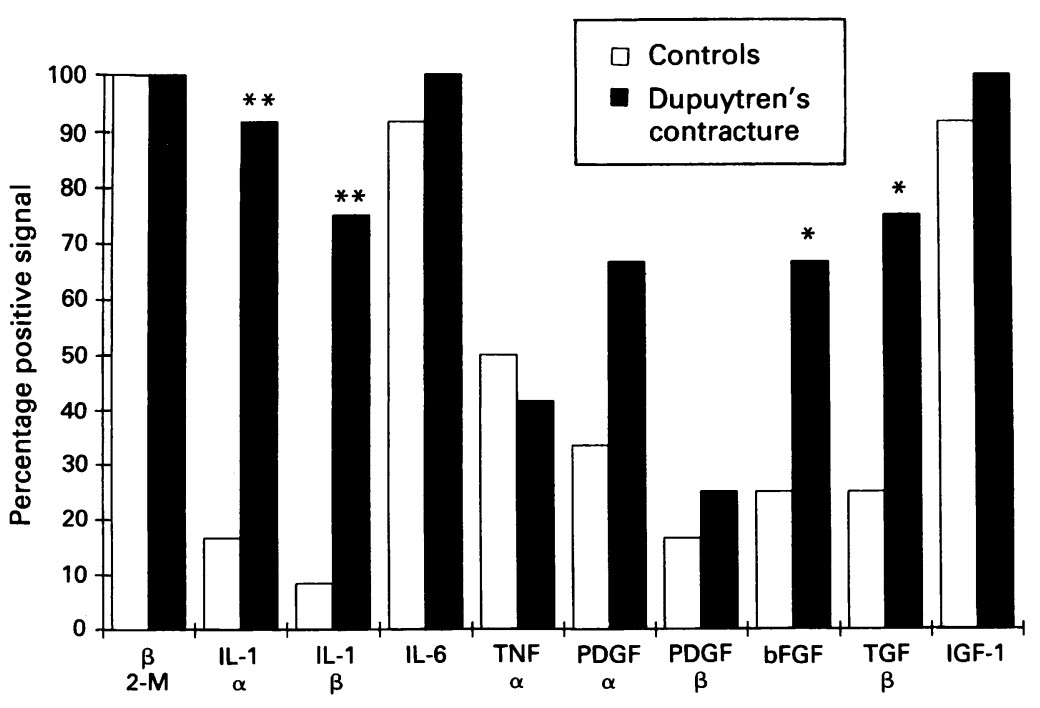

Figure 2 Expression of PRF MRNAs as detected by RT/PCR. and TNF $a$ to a similar degree, IL-1 $a, \mathrm{IL}-1 \beta$, $\mathrm{bFGF}$ and TGF $\beta$ were expressed in a significantly greater number of Dupuytren's contracture tissues than controls. A similar trend was also observed for PDGF $a$ and $\operatorname{PDGF} \beta$, although here, the differences between the groups was not significant.

It is important to emphasise that the expression of these factors is not specific for Dupuytren's contracture; similar peptide regulatory factors are produced by macrophages derived from healing wounds, for example, where they are likely to have an important role in promoting tissue repair. ${ }^{15}$ The interest of our data, however, relates to the fact that expression of these peptide regulatory factors in palmar tissue is clearly inappropriate, in the absence of an external stimulus to their production. What is the relevance of these findings to the pathogenesis of Dupuytren's contracture? IL-1 causes fibroblast proliferation : $\eta$ vitro, ${ }^{16}$ possibly by inducing expression of transcriptional factors such as $c-f o s, c-j u n$, and $c-m y c^{17}$; thus inappropriate expression of either IL-1 species alone could account for the local proliferation of fibroblasts seen in active Dupuytren's contracture. The mitogenic effects of IL-1 would probably be potentiated by coexpression with other factors identified in this study, such as basic FGF, ${ }^{18}$ TGF $\beta,{ }^{19}$ and PDGF $a$ or PDGF $\beta .^{20}$ Indeed, perhaps the combined expression of several such factors would be necessary to sustain the chronic fibroblast proliferation and matrix production which occurs in Dupuytren's contracture. The expression of TGF $\beta$ is also of interest because, besides its effect on cellular proliferation, ${ }^{21}$ it acts as chemotactic factor for fibroblasts ${ }^{22}$ and enhances both collagen and fibronectin production by cultured fibroblasts both in vitro and in vivo. ${ }^{23} 24$ These actions are, of course, highly relevant to the pathogenesis of Dupuytren's contracture, particularly in the later stages where deposition of extracellular matrix may predominate over fibroblast proliferation.

It might be argued that the above peptide regulatory factors should have been uniformly expressed in all Dupuytren's contracture tissues and none of the controls if they were truly responsible for the disease process. The histological picture in Dupuytren's contracture is extremely variable, however, such that areas of intense cellular proliferation may be contiguous with areas of relatively inactive tissue. ${ }^{25}$ In view of this, it is hardly surprising that there should be some variability in gene expression among the Dupuytren's contracture tissues analysed.

Although we have documented specific abnormalities of peptide regulatory factor gene expression in Dupuytren's contracture when compared with control tissue, we have no information on whether or not these factors are translated into protein or released to exert their various effects in vivo; further studies will be needed to clarify this point. It is similarly unclear from our study which cells in the Dupuytren's lesion are responsible for 
the expression of these factors. In this regard, recent studies have drawn attention to the presence of macrophages in the Dupuytren's contracture lesion ${ }^{25}$ and these cells are certainly capable of producing most of the factors identified in the current study. ${ }^{26}$ The Dupuytren's contracture fibroblast itself would be another possible source, however, and formal localisation studies, using other techniques such as immunohistochemistry or in situ hybridisation will have to be done to investigate this further.

In summary, our studies show that several peptide regulatory factor genes are inappropriately expressed in Dupuytren's contracture. Although a great deal of further work is needed to determine the precise role of these factors in its pathogenesis, our findings raise the possibility that Dupuytren's contracture may arise as the result of local abnormalities in the regulation of cytokine and growth factors which act locally in an autocrine or paracrine manner to stimulate fibroblast growth and matrix production.

We thank Professor DL Hamblen for helpful discussions, constant encouragement, and the generous use of his laboratory facilities. This study was supported by a grant to the authors from the Scottish Hospitals Endowments Research Trust (SHERT 1066) and a grant to SHR by the Wellcome Trust.

1 McFarlane RM, McGrouther DA, Flint MH. Dupuytren's disease: biology and treatment. Edinburgh: Churchill Livingstone, 1990.

2 Brickley-Parsons D, Glimcher MJ, Smith RJ, Albin R Adams J. Biochemical changes in collagen of the palmar fascia in patients with Dupuytren's disease. $\mathcal{F}$ Bone foint Surg 1981;63A:787-97.

3 Tunn S, Gurr E, Delbruck A, Buhr T, Flory J. The distribution of unsulphated glycosaminoglycans in palmar fascia from patients with Dupuytren's disease and healthy subjects. 7 Clin Chem 1988;26:7-14.

4 Murrell GAC, Francis MJO, Bromley L. Free radicals and Dupuytren's contracture, Br Med f 1987;295:1373-5.

5 Ling RSM. The genetic factor in Dupuytren's disease. $f$ Bone foint Surg 1963;45-B:709-18.

6 James JIP. The relationship of Dupuytren's contracture and epilepsy. Hand 1969;1:47-9.

7 Delli-Bovi PD, Curatola AM, Kern FG. An oncogene isolated by transfection of Kaposi's sarcoma DNA encodes a growth factor that is a member of the FGF family. Cell 1987;50:729-37.

8 Azzarone B, Failly-Crepin C, Daya-Grosjean L, ChaponNeir C, Gabbiani C. Abnormal behaviour of cultured fibroblasts from nodule and non-affected aponeurosis of Dupuytren's disease. F Cell Physiol 1983;117:353-61.

9 Barsky SH, Gopalkrishna R. Isolation of a myofibroblast growth factor from human breast carcinoma cell lines. Biochem Biophys Res Comm 1987;149:1125-31.

10 Kawasaki ES, Wang AM. Detection of gene expression. In: Erlich HA, ed. PCR technology. New York: Stockton Press, 1989:89-98.

11 Chomczynski P, Sacchi N. Single-step method of RNA isolation by acid guanidinium thiocyanate-phenol-

12 Kwok S, Higuchi R. Avoiding false positives with PCR. Nature 1989;339:237-8.

13 Deveraux J, Haeberli P, Smithies O. A comprehensive set of sequence analysis programs for the VAX. Nucleic Acids Res 1984;12:387-95.

14 Dallman MJ, Larsen CP, Morris PJ. Cytokine gene transcription in vascularised organ grafts: analysis using semiquantitative polymerase chain reaction. $\mathcal{f} \operatorname{Exp} M e d$ $1991 ; 174: 493-6$.

15 Rappolee DA, Mark DI, Banda MJ, Werb Z. Wound macrophages express TGF alpha and other growth factors in vivo: analysis by mRNA phenotyping. Science tors in vivo: an

16 Postlethwaite AE, Lachman LB, Kang AH. Induction of fibroblast proliferation by interleukin-1 derived from human monocytic leukemia cells. Arthritis Rheum 1984 27:995-1001.

17 DiGiovine FS, Duff GW. Interleukin-1: the first interleukin. Immunology Today 1990;11:13-20.

18 Gospodarowicz D. Fibroblast growth factor: Chemical structure and biologic function. Clin Orthop Rel Res 1990;257:231-48.

19 Lyons RM, Moses HL. Transforming growth factors and the regulation of cell proliferation. Eur $\mathcal{F}$ Biochem 1990, 187:467-73.

20 Ross R. Platelet-derived growth factor. Lancet 1989;i: 1179-82.

21 Leof EB, Proper JA, Goustin AS, Shipley GD, DiCorletto $\mathrm{PE}$, Moses HL. Induction of c-sis mRNA and activity similar to platelet-derived growth factor by transformin growth factor beta: A proposed model for indirect mitogenesis involving autocrine activity. Proc Natl Acad Sci USA 1986;83:2453-7.

22 Postlethwaite AE, Keski-Oja J, Moses HL, Kang AH Stimulation of the chemotactic migration of human fibroblasts by transforming growth factor beta. $7 \mathrm{Exp}$ Med 1987;165:251-6.

23 Ignotz RA, Endo T, Massague J. Regulation of fibronectin and type I collagen mRNA levels by transforming and type I collagen mRNA levels by transformi

24 Roberts AB, Sporn MB, Assoian RK, et al. Transformin growth factor type beta: Rapid induction of fibrosis and angiogenesis in vivo and stimulation of collagen formation in vitro. Proc Natl Acad Sci USA 1986;83:4167-71.

25 Andrew JG, Andrew SM, Turner B. An investigation into the role of inflammatory cells in Dupuytren's disease. $f$ Hand Surg 1991;16B:267-71.

26 Nathan CF. Secretory products of macrophages. $\mathcal{f}$ Clin Invest 1987;79:319-26. 